\title{
Urologists' knowledge base and practice patterns in Peyronie's disease. A national survey of members of the italian andrology society
}

\author{
Gianni Paulis ${ }^{1}$, Francesca Pisano ${ }^{2}$, Alessandro Palmieri ${ }^{3}$, Tommaso Cai ${ }^{4}$, Fabrizio Palumbo ${ }^{5}$, \\ Bruno Giammusso ${ }^{6}$ \\ ${ }^{1}$ Peyronie's Care Center, Department of Uro-Andrology, Castelfidardo Medical Team, Rome, Italy; \\ 2 Department of Urology, Fundacio Puigvert, Autonomous University of Barcelona, Spain; \\ ${ }^{3}$ Department of Neurosciences, Reproductive Sciences and Odontostomatology, University of Naples Federico II, Naples, Italy; \\ ${ }^{4}$ Department of Urology, Santa Chiara Regional Hospital, Trento, Italy; \\ ${ }^{5}$ Department of Urology, Di Venere Hospital, Bari, Italy; \\ ${ }^{6}$ Urology Clinic, Policlinic "Morgagni", Catania, Italy.
}

\section{Summary Peyronie's disease is a chronic inflammatory disease involving the formation of plaque in} the tunica albuginea of the corpora cavernosa, resulting in penis deformity. It is often associated with penile pain, especially in younger patients, but it is not rare for pain to be absent; the disease is also associated with erectile dysfunction and a depressive state in a large percentage of cases.

Objective: Aim of our study was to explore the basic knowledge base and diagnostic and therapeutic practice patterns in Peyronie's disease (PD) of a large number of physicians belonging to the Italian Andrology Society (SIA).

Methods: Our survey is based on two questionnaires which were $e$-mailed to the members of the SIA. The first questionnaire explored diagnostic and therapeutic practice patterns of SIA physicians, while the second questionnaire focused on their knowledge of the disease, as well as their training and level of experience in the specific field. We then planned to compare our outcomes with similar PD surveys from other countries.

Results: The first questionnaire was answered by 142 SIA physicians. The second questionnaire was answered by 83 SIA physicians. Most respondents (74.6\%) chose penile ultrasonography as first-line diagnostic approach and $47.1 \%$ prefer to perform a color Doppler ultrasound after pharmaco-induced erection. Concerning the therapeutic practice patterns in active stage of the disease, most respondents (99.29\%) prefer conservative medical therapy. Additionally, most respondents (64.78\%), when failure of conservative treatment had been established, considered surgical treatment necessary, specifically corporoplasty, which may be associated with other techniques.

Conclusions: The results of our survey show that, in comparison to their foreign counterparts, Italian SIA uro-andrologists have a more proactive diagnostic approach right from when patients first present. When PD is still in its active stage, SIA uro-andrologists mostly opt for medical therapy. In advanced disease or if conservative treatment fails, our survey indicates a greater preference for surgical treatment. Answers to the theoretical knowledge questions showed that SIA physicians have a good understanding of the disease's etiology, epidemiology, and clinical picture, and of the appropriate indications for treatment.

KEY WORDS: Peyronie's disease; Penile curvature; Erectile dysfunction; Peyronie's disease treatment; Practice patterns; Survey.

Submitted 28 June 2021; Accepted 9 August 2021

\section{INTRODUCTION}

Peyronie's disease (PD) is a chronic inflammatory disease of the tunica albuginea of the corpora cavernosa, involving the formation of a fibrous or even calcified plaque which almost always causes penile curvature and/or deformity (divot, hourglass deformity, shortening). It is often associated with penile pain, especially in younger patients, but it is not rare for pain to be absent; the disease is also associated with erectile dysfunction (ED) (in over 30\% of cases) and a depressive state in a large percentage of cases (48\%) (1-3). Although the exact etiology of the disease is unknown, according to the most credited theory, injury, or micro-traumas to the tunica albuginea of the corpora cavernosa of the penis play a decisive role in its pathogenesis (4-7). Penile trauma, by causing delamination of the layers of the tunica albuginea with consequent rupture of the small perforating blood vessels, is thought to result in the formation of a small hematoma which triggers the inflammatory process $(5,6)$. Supposedly, fibrin accumulation then causes recruitment of inflammatory cells (neutrophils and macrophages), with consequent overproduction of pro-inflammatory fibrogenic cytokines and reactive oxygen species (ROS) (7-12). Once the inflammatory process has been triggered, the subsequent chain of biochemical events is then thought to result in hyperproliferation of fibroblasts and myofibroblasts, leading to excessive production and deposition of collagen at the site (8). Genetic predisposition is certain to play a fundamental role in the possibility of developing the disease, with an autosomal dominant inheritance pattern (13-16). Several epidemiological studies have found that disease prevalence in adult males varies between 3.2\% and 13\%; a study by La Pera et al. (2001) detected a 7.1\% prevalence of PD in Italian males (17-19). The disease generally affects adult males of 50-60 years of age, but in the past few years a considerable increase in PD incidence has been reported in patients under 40 years of age (10.8\%-16.9\% of cases) $(20,21)$. In its first stages, PD is characterized by the presence of an inflammatory area (corresponding to the plaque) in which fibroblasts and myofibroblasts produce excess collagen $(8,22,23)$. Several studies have shown that local hyperproduction of collagen 
in PD is directly connected with elevated production of pro-inflammatory fibrogenic cytokines, among which the most important are transforming growth factor beta-1 (TGFB1) and platelet-derived growth factor (PDGF) (6, 24-26).

The natural history of the disease has two stages: an initial remodeling phase, which is the inflammatory stage and lasts about 12-18 months; the second phase consists in stabilization of the disease: in this phase, pain is typically absent, while the penile deformity stops progressing (27-29). Conservative medical treatment is indicated in the first (active) stage and includes oral therapy, local intralesional therapy, and physical treatment: vitamin E, colchicine, tamoxifen, potaba, antioxidants, etc.; injections with verapamil, pentoxifylline, hyaluronic acid, corticosteroids, collagenase clostridium histolyticum (CCH/Xiaflex-Xiapex), interferon- $\alpha 2 b$ (IFNa2b); extracorporeal shock wave therapy (ESWT), iontophoresis, penile extender devices, vacuum devices, etc. (30-37).

In particular, use of $\mathrm{CCH}$ was approved in the USA in 2013 by the US Food and Drug Administration (FDA) only in patients with stable PD; the same guidelines were issued by the American Urological Association, which recommends its use in stable disease (38). However, use of $\mathrm{CCH}$ has recently been proposed even in the acute (initial) phase of the disease $(32,39)$. Surgical therapy is indicated when the disease has been stable for at least 6 months and sexual intercourse has become impossible due to the presence of severe penile deformity or treatment-resistant ED; surgical treatment is also indicated when there is extensive calcification of the plaque, or when patients want a rapid, assured result (40-44).

Despite the ample range of treatments proposed in the literature, there is no complete consensus among urologists about modality of therapeutic approach; this is partly due to an incomplete knowledge of the pathophysiological mechanisms of the disease. It is a fact that none of the therapeutic options mentioned in international guidelines on PD has a grade A recommendation (45-48).

Over the past few years, several articles have been published that focused on PD surveys and questionnaires (49-54). The surveys described in the articles explored and assessed the basic knowledge and different diagnostic and therapeutic approaches of urologists, and these articles also found that practice patterns vary, especially with regards to treatment. Aim of our study was to explore the basic knowledge and diagnostic and therapeutic practice patterns in $\mathrm{PD}$ in a large number of physicians belonging to the Italian Andrology Society (SIA).

\section{Materials AND MEthods}

The survey was carried out last year (2020). Two questionnaires were e-mailed by the SIA office to all its uroandrologist members. A reminder e-mail was then sent to non-responders about one month after the initial mailing. No compensation was offered for completion of the questionnaires. The questionnaires used templates from the Google Doc web platform (docs.google.com).

They were shared with and approved by the SIA Board and Scientific Committee.

The first questionnaire comprised 5 multiple-choice questions and explored the diagnostic and therapeutic approach of SIA physicians (see Table 1) (some questions required more than one answer as first question).

The second questionnaire (see Table 2) contained 15 multiple-choice questions. The first 11 questions explored the uro-andrologists' basic knowledge on PD.

The remaining 4 questions focused on the physicians' specialty, as well as their level of experience and clinical practice in the specific field.

The analysis of the results did not require any particular statistical software, since we merely collected the percentages of answers to each question. Finally, adequacy of answers to the treatment-specific questions of the second questionnaire was assessed based on current approaches in the scientific literature on PD.

\section{REsULts}

The first questionnaire was answered by 142 specialists (urologists and andrologists).

The second questionnaire was answered by 83 specialists (urologists and andrologists).

Results are reported in Table 1 and 2.

\section{Discussion}

Most SIA respondents chose penile ultrasonography as first-line diagnostic approach (74.6\%); most respondents prefer to perform a color Doppler ultrasound after pharmaco-induced erection (47.1\%), while the remaining 27.4\% opt for a flaccid penile ultrasound, using color Doppler ultrasound with pharmaco-induced erection only in cases where ED is also present. However, it must be pointed out that $9.1 \%$ of SIA respondents believes simple palpation of the penile nodule to be a sufficient diagnostic method.

In most other similar surveys on PD in the literature (4954), diagnosis is not discussed; when it was included as an item, penile ultrasonography was deemed to be necessary in $22 \%$ to $28.2 \%$ of cases $(52,54)$.

Although international guidelines do not consider penile ultrasound mandatory, our survey shows instead that most Italian uro-andrologists who responded to the SIA questionnaire $(75.3 \%)$ believes a diagnostic imaging test should be performed (40, 45-48).

With regards to therapeutic practice patterns in active stage $\mathrm{PD}$, we found that in almost all cases SIA respondents (99.29\%/141 out of 142) favor conservative medical therapy. In our survey, the conservative approach almost always (85.9\%/122 out of 142) consisted in oral therapy associated most of the time with a physical treatment (vacuum device, ESWT, ultrasound therapy, iontophoresis, laser therapy) or penile injections (collagenase, verapamil, and/or corticosteroid, etc.). The oral therapy varies: besides several antioxidants (see results), it includes colchicine, potaba, pentoxifylline, and PDE-5 inhibitors. Comparing our survey with other existing surveys in the literature, we found the closest approach to ours to be that of the US survey in which LaRochelle $\&$ Levine (2007) found that $72 \%$ of urologists preferred medical treatment for PD, while 29\% did not believe any treatment was necessary, and 28\% preferred surgery only in case of associated severe curvature (50). In our survey, however, the "non-therapeutic" approach was only supported by one respondent out of 
Table 1.

Replies to first questionnaire.

\begin{tabular}{|c|c|c|}
\hline Questions & Answers & $\%$ (Number) \\
\hline $\begin{array}{l}\text { 1) After first seeing patients presenting with Peyronie's disease, } \\
\text { before proceeding to treatment... }\end{array}$ & $\begin{array}{l}\text { I simply perform palpation and locate the penile plaque } \\
\text { I refer the patient for a flaccid penile ultrasound } \\
\text { I refer the patient for a penile dynamic Doppler ultrasound } \\
\left({ }^{*}\right) \text { I refer the patient for a penile dynamic Doppler ultrasound only with concomitant ED } \\
\text { I refer the patient for an MRI of the corpora cavernosa } \\
\left({ }^{*}\right) \text { I refer the patient for the above-mentioned exam even though I did not find any palpable nodule } \\
\text { Other } \\
\text { - palpation and photograph of erect penis } \\
\text { - unspecified penile ultrasonography } \\
\text { - photograph of erect penis } \\
\text { - stretched penile length measurement } \\
\text { - invalid answers }\end{array}$ & $\begin{array}{l}17.6 \% \text { ( } 25 \text { out of } 142) \\
27.4 \% \text { (39 out of } 142) \\
47.1 \%(67 \text { out of } 142) \\
26.05 \% \text { ( } 37 \text { out of } 142 \\
0.7 \%(1 \text { out of } 142) \\
9.1 \% \text { (13 out of } 142) \\
\\
0.7 \% \text { (1 out of } 142) \\
0.7 \% \text { (1 out of } 142) \\
4.2 \%(6 \text { out of } 142) \\
0.7 \% \text { (1 out of } 142) \\
0.7 \% \text { (1 out of } 142)\end{array}$ \\
\hline $\begin{array}{l}\text { 2) Your first therapeutic approach in patients with Peyronie's } \\
\text { disease (in its active stage, when it has not stabilized) } \\
\text { is the following }\end{array}$ & $\begin{array}{l}\text { Conservative medical therapy } \\
\text { Surgical therapy } \\
\text { No therapy }\end{array}$ & $\begin{array}{l}99.2 \%(141 \text { out of } 142) \\
0 \%(0) \\
0.7 \%(1 \text { out of } 142)\end{array}$ \\
\hline $\begin{array}{l}\text { 3) If you opt for a conservative medical approach, } \\
\text { what treatment do you prescribe? }\end{array}$ & $\begin{array}{l}\text { Oral therapy + physical treatment (Generic oral antioxidants, vitamin E, colchicine, avocado + soybean, potaba, } \\
\text { pentoxifylline, PDE-5 inhibitors), various types of physical treatment (vacuum device, ESWT, ultrasound, laser therapy, } \\
\text { iontophoresis with verapamil and/or cortisone, iontophoresis with pentoxifylline and/or verapamil) } \\
\text { Oral therapy only } \\
\text { - oral antioxidants (single or in combination: vitamin E, propolis, blueberry, astaxanthin, paba, arginine, Centella asiatica) } \\
\text { - vitamin E + tamoxifen } \\
\text { - antioxidants + colchicine } \\
\text { - potaba } \\
\text { - oral cortisone } \\
\text { - antioxidants + oral cortisone } \\
\text { - unspecified } \\
\text { Penile injections only } \\
\text { - collagenase (CCH) with modeling } \\
\text { - verapamil } \\
\text { - verapamil + corticosteroid } \\
\text { - PRP (platelet rich plasma) } \\
\text { - unspecified agent } \\
\text { Physical treatment only } \\
\text { - vacuum device } \\
\text { - ESWT } \\
\text { - iontophoresis } \\
\text { - iontophoresis + ESWT } \\
\text { - iontophoresis + ESWT + ultrasound therapy } \\
\text { Oral therapy + penile injections } \\
\text { Oral therapy + physical treatment + penile injections } \\
\text { Oral therapy + vacuum device } \\
\text { Conservative medical therapy on a case-by-case basis } \\
\text { No therapy }\end{array}$ & $\begin{array}{l}35.9 \% \text { (51 out of } 142) \\
17.6 \% \text { (25 out of } 142) \\
-76.0 \% \text { (19 out of } 25) \\
-4.16 \% \text { (1 out of } 25) \\
-4.0 \% \text { (1 out of } 25) \\
-4.0 \% \text { (1 out of } 25) \\
-4.0 \% \text { (1 out of } 25) \\
-4.0 \% \text { (1 out of } 25) \\
-4.0 \% \text { (1 out of } 25) \\
7.7 \% \text { (11 out of } 142 \text { ) } \\
-63.6 \% \text { (7 out of } 11) \\
-9.09 \% \text { (1 out of } 11) \\
-9.09 \% \text { (1 out of } 11) \\
-9.09 \% \text { (1 out of } 11) \\
-9.09 \% \text { (1 out of } 11) \\
3.5 \% \text { (5 out of } 142) \\
-20.0 \% \text { (1 out of } 5) \\
-20.0 \% \text { (1 out of } 5) \\
-20.0 \% \text { (1 out of } 5) \\
-20.0 \% \text { (1 out of } 5) \\
-20.0 \% \text { (1 out of } 5) \\
32.3 \% \text { (46 out of } 142) \\
0.7 \% \text { (1 out of } 142) \\
0.7 \% \text { (1 out of } 142) \\
0.7 \% \text { (1 out of } 142) \\
0.7 \% \text { (1 out of } 142)\end{array}$ \\
\hline $\begin{array}{l}\text { 4) How long after the start of conservative medical treatment } \\
\text { do you consider it to have failed? }\end{array}$ & $\begin{array}{l}\text { After } 3 \text { months } \\
\text { After } 6 \text { months } \\
\text { After } 9 \text { months } \\
\text { After } 12 \text { months } \\
\text { After } \\
\quad \text { - no exact time limit } \\
\quad \text { - inadequate answers }\end{array}$ & $\begin{array}{l}21.1 \% \text { (30 out of } 142) \\
44.3 \% \text { ( } 63 \text { out of } 142 \\
9.8 \%(14 \text { out of } 142) \\
19.01 \% \text { ( } 27 \text { out of } 142) \\
\\
0.7 \% \text { (1 out of } 142) \\
4.9 \% \text { (7 out of } 142)\end{array}$ \\
\hline 5) If consenvative medical treatment fails, what do you do? & $\begin{array}{l}\text { I refer the patient for surgery } \\
\text { - corporoplasty } \\
\text { - corporoplasty + grafting } \\
\text { - corporoplasty + implant } \\
\text { - corporoplasty + implant only if ED is present } \\
\text { - plaque excision + grafting } \\
\text { - plaque excision + grafting + implant } \\
\text { - it depends on the specific case } \\
\text { - unspecified surgical treatment } \\
\text { I try out another medical treatment } \\
\text { - intraplaque collagenase (CCH) injection with modeling } \\
\text { - intraplaque corticosteroid injection } \\
\text { - intraplaque corticosteroid injection + antioxidants } \\
\text { - generic intraplaque injection } \\
\text { - injections with verapamil or orgotein + antioxidants } \\
\text { - oral antioxidants } \\
\text { - generic iontophoresis (no drug specified) } \\
\text { - ESWT } \\
\text { - ESWT + iontophoresis } \\
\text { - vacuum device } \\
\text { - unspecified physical treatment } \\
\text { - oral antioxidants + unspecified physical treatment } \\
\text { - oral antioxidants + iontophoresis with pentoxifylline } \\
\text { - new therapy attempt with a different unspecified drug } \\
\text { - it depends on the case } \\
\text { № answer }\end{array}$ & $\begin{array}{c}64.7 \% \text { (92 out of } 142) \\
-21.8 \% \text { (31 out of } 142) \\
-4.9 \% \text { ( } 7 \text { out of } 142) \\
-5.6 \% \text { (8 out of } 142) \\
-2.8 \% \text { (4 out of } 142) \\
-7.7 \% \text { (11 out of } 142) \\
-2.1 \% \text { ( } 3 \text { out of } 142) \\
-14.7 \% \text { (21 out of } 142 \text { ) } \\
-4.9 \% \text { (7 out of } 142) \\
31.6 \% \text { (45 out of } 142) \\
-4.9 \% \text { (7 out of } 142) \\
-0.7 \% \text { (1 out of } 142) \\
-0.7 \% \text { (1 out of } 142) \\
-2.1 \% \text { (3 out of } 142) \\
-0.7 \% \text { (1 out of } 142) \\
-1.4 \% \text { (2 out of } 142) \\
-0.7 \% \text { (1 out of } 142) \\
-4.2 \% \text { ( } 6 \text { out of } 142) \\
-0.7 \% \text { (1 out of } 142) \\
-0.7 \% \text { (1 out of } 142) \\
-0.7 \% \text { (1 out of } 142) \\
-0.7 \% \text { (1 out of } 142) \\
-0.7 \% \text { (1 out of } 142) \\
-0.7 \% \text { (1 out of } 142) \\
11.9 \% \text { (17 out of } 142 \text { ) } \\
3.5 \% \text { (5 out of } 142)\end{array}$ \\
\hline
\end{tabular}

$\left({ }^{*}\right)=$ possible further answer

ED = erectile dysfunction; MRI = Magnetic resonance imaging; $E S W T=$ extracorporeal shock wave therapy: $P D E-5=$ phosphodiesterase-5 inhibitors; $C C H=$ collagenase clostridium histolyticum; $P R P=$ platelet rich plasma. 
Table 2.

Replies to second questionnaire.

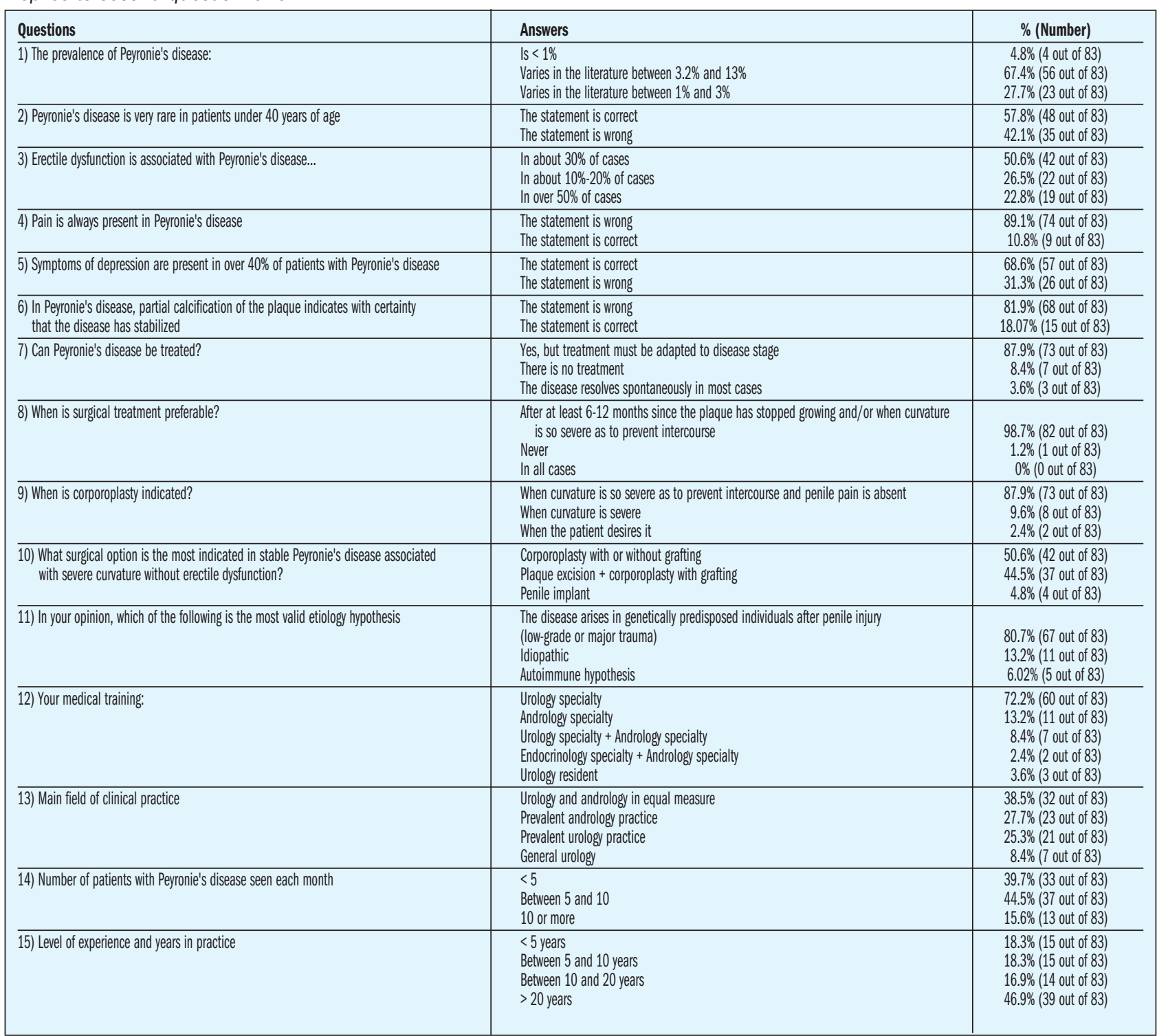

$142(0.7 \%)$. With respect to the practice of "not treating" PD patients, in their 2015 survey of urologists belonging to the American Urology Association (AUA), Sullivan et al. found that $26 \%$ of specialists believed PD to be a condition that does not warrant any treatment, while 59\% of urologists decided to initiate medical treatment, and 38\% of urologists thought an initial period of observation was necessary before deciding on any treatment (52). A PD survey by Hauck et al. (2005) found that 62\% of German urologists preferred medical treatment, while $26.9 \%$ preferred surgical treatment, and only $6.8 \%$ did not consider any treatment warranted (49).

When comparing the treatment approaches found by our survey with the treatment practice patterns of foreign colleagues, we obtained the following results.

A recent US PD survey (Oberlin et al., 2016) found that $82 \%$ of urologists opted for intralesional injections, while in $18 \%$ of cases a surgical approach was preferred (53). A Korean PD survey published in 2014 found that in the initial phase of the disease most urologists preferred oral therapy with the following agents: vitamin E (80.2\%), phosphodiesterase-5 (PDE-5) inhibitors (27.4\%), potaba (20.1\%), carnitine (16.7\%), colchicine (11.7\%), tamoxifen (10.4\%), pentoxifylline (7.0\%). However, $71.9 \%$ of Korean urologists also used intralesional injections, while $41.8 \%$ preferred to start intralesional therapy only when oral therapy had failed (54).

In their Illinois- and Wisconsin-based PD survey, LaRochelle E Levine (2007) found that $81 \%$ of urologists recommended vitamin $\mathrm{E}$ for $\mathrm{PD}$ patients, the next most frequent therapeutic choice (35\%) was treatment with potaba, and only 15\%-20\% of urologists preferred instead medical treatment with non-steroidal anti-inflammatory drugs (NSAIDs), colchicine, penile injections with steroids, interferon, verapamil, and topical verapamil (50).

In their German survey, Hauck et al. (2005) analyzed the practice patterns of urologists who preferred a conservative medical treatment and found that $57.8 \%$ of them used the 
following oral agents (in decreasing order of preference): potaba, vitamin E, tamoxifen, colchicine. Among urologists who opted for medical treatment, $13.83 \%$ used injection therapy with the following agents (in decreasing order of preference): corticosteroids, verapamil, superoxide-dismutase (SOD). Among urologists opting for conservative medical treatment, $28.37 \%$ preferred physical treatment with the following methods (in decreasing order of preference): ESWT, radiation therapy, iontophoresis (49).

Sullivan et al. (2015), in their PD survey of members of the American Urology Association, found that physicians who had decided to treat their patients conservatively favored the following therapies (in decreasing order of preference): oral therapy (81\%) with vitamin E, colchicine, potaba; intralesional injection therapy (9\%) with verapamil, corticosteroids, interferon (52).

In our survey of SIA members, a broad majority of physicians judged therapeutic failure to occur when the initial conservative therapy gave no results after 6-12 months (73.23/104 out of 142); additionally, most uro-andrologists $(64.78 \% / 92$ out of 142), when failure of conservative treatment had been established, considered surgical treatment necessary, specifically corporoplasty, which may be associated with other techniques (grafting, plaque excision/incision, penile implant). Comparing our survey to other surveys in the literature, we found no comparable questions on the time after which medical therapy is seen as having failed. Whereas with respect to the therapeutic approach taken when conservative treatment has failed, in other surveys we found that $67.6 \%$ of Korean urologists decided surgical treatment was indicated, specifically corporoplasty (84.1\%/190 out of 226), plaque excision/incision + grafting (42.9\%/97 out of 226), or prosthesis implant (14.2\%/32 out of 226) (54).

In our second questionnaire, in response to the question about the prevalence of PD, most SIA respondents (67.4\%) answered that prevalence of the disease varies between $3.2 \%$ and $13 \%$, and this matches the data in the literature $(12,55,56)$. We found the same question regarding disease prevalence in the US survey by LaRochelle \& Levine (2007) which established that $41 \%$ of interviewed urologists believed PD occurs in less than 1\% of men (50). The PD survey by Sullivan et al. (2015) found that 21\% of urologists believed the prevalence of PD to be less than $1 \%$, while 5\% believe the prevalence to be over 10\% (52).

Our second questionnaire also asked whether PD is very rare in patients under 40 years of age; $57.8 \%$ of SIA respondents believes PD is very rare in this age group, while the remaining respondents believe this is false.

We only found a similar question in the U.S. survey by LaRochelle \& Levine (2007) which reported that only 9\% of responding urologists believe PD cannot present in men under 40 years of age (50). The literature on this topic informs us that PD is all but rare in patients under 40 ; as a matter of fact, a number of articles report a $10.8 \%-16.9 \%$ incidence in this age group $(20,21)$. A more recent article by Stuntz et al. (2016) should be mentioned, in which a study of a large sample of US population found that the mean age of PD patients has decreased and is now 48.9 years, and prevalence of the disease in the 18-to-34-year age range is as high as $29.76 \%$ (57).

The answers to our survey in response to the question about whether ED is present in PD showed that most SIA members $(50.6 \%)$ believe ED is associated with PD in about $30 \%$ of cases, and this matches the data in the literature (58-60). A similar question in the LaRochelle $\&$ Levine PD survey revealed that $37 \%$ of responding urologists did not believe there is a close association between PD and ED (50).

In answer to the same question, in the PD survey by Sullivan et al. (2015), 40\% of urologists stated that ED is present in PD in less than $30 \%$ of cases (52). In the Korean PD survey, on the other hand, only $2.1 \%$ of Korean urologists found ED in patients with PD (54). The international literature on ED in patients with PD reports that $\mathrm{ED}$ is present in a proportion that varies between $31.5 \%$ and $60.1 \%(3,17,29,40,58,59)$.

Analyzing the question in our survey on the presence of pain in PD, $89.15 \%$ of SIA members believes pain is not always present in PD. In the Korean survey, $13.5 \%$ of Korean urologists found erection to be painful in patients with PD (54). In the international literature, incidence of pain in PD varies between 20\% and 70\% $(1,17,60)$.

In response to our survey question on the presence of symptoms of depression in PD, most SIA members (68.6\%) answered that symptoms of depression are present in PD patients in over $40 \%$ of cases. In response to a similar question in the PD survey by Sullivan et al. (2015) most respondents $(75 \%)$ stated that a diagnosis of depression can be made in less than $25 \%$ of PD patients (52). In the literature, the prevalence of psychological problems in PD patients is very high, ranging from $62.4 \%$ to $81 \%$ of cases $(30,59,61,62)$. An interesting study published by Nelson (2008) on the same topic detected a $48 \%$ prevalence of clinically significant depression in patients suffering from PD (63). With respect to our survey question on partial calcification of plaque and its clinical significance in terms of disease state, most SIA uro-andrologists $(81.96 \%)$ believes this situation does not necessarily correspond to disease stabilization.

The above-mentioned PD surveys had no similar questions. However, an interesting article by Levine et al. (2013) dealt with this topic in depth, postulating that plaque calcification does not appear to be an indicator of mature, stabilized disease, as in their study the authors detected that in $54.2 \%$ of patients with plaque calcification, symptoms had arisen less than 6-12 months earlier (64).

When asked whether it is possible to treat PD, $87.9 \%$ of SIA uro-andrologists answered affirmatively, specifying that treatment must be adapted to disease stage. A more detailed account of the type of practice patterns has already been given with regard to treatment-specific questions.

When asked in what cases surgical therapy is preferable, $98.7 \%$ of SIA members answered that a surgical approach is indicated in the stable stage of the disease, when the plaque has stopped growing at least 6-12 months before and/or penile deformity already makes sexual intercourse impossible. This choice of surgery in case of stable disease or severe curvature is widely supported in the literature and by international urology guidelines $(28,30,38,40$, $41,47,48,65-69)$.

With respect to the question on the correct indication for the performance of corporoplasty, $87.9 \%$ of SIA uroandrologists answered they believed this type of surgery to 
be indicated in patients with severe penile curvature and in the absence of penile pain, a sign of disease stabilization. There is broad consensus in the field of urology on this approach, as well $(28,30,38,40,41,47,48,65-69)$. With respect to the correct surgical indication in stable PD associated with severe curvature and in the absence of ED, $50.6 \%$ of SIA members answered that they opt for corporoplasty, reflecting - even in this case - the most frequent approach in the international literature.

In answer to the question on their opinion on which of the most frequent etiology hypotheses for PD is more likely valid, $80.7 \%$ of SIA uro-andrologists believes PD onset occurs in genetically predisposed subjects and following penile injury (low-grade or major trauma). The remaining specialists believe the more likely etiology is autoimmune $(6 \%)$ or idiopathic $(13.2 \%)$. Even in this case, the majority opinion (80.7\%) in our survey is supported by several studies (4-7, 13-16, 70-73).

Our questionnaire also included a question on the specialist training of the physicians who participated in the survey. The answers yielded the following data: Urology specialty in $72.2 \%$ of cases; Andrology specialty in $13.2 \%$ of cases; Urology specialty + Andrology specialty in $8.4 \%$ of cases; Endocrinology specialty + Andrology specialty in $2.4 \%$ of cases; Urology residents were $3.6 \%$. It must be borne in mind, however, that this result reflects the training of SIA members who participated in the survey and is very likely not identical with the training of all SIA practitioners.

The specific question on what clinical field respondent mainly practiced was answered as follows: urology and andrology in equal measure in $38.5 \%$ of cases; prevalent andrology practice in $27.7 \%$ of cases; prevalent urology practice in $25.3 \%$ of cases: general urology practice in $8.4 \%$ of cases. With respect to the number of patients suffering from PD who are seen each month by SIA physicians, the result was the following: between 5 and 10 patients per month in $44.5 \%$ of cases; fewer than 5 patients per month in $39.7 \%$ of cases; 10 or more patients per month in $15.6 \%$ of cases. With respect to their experience and years in practice,

SIA members answered as follows: over 20 years in $46.9 \%$ of cases; between 5 and 10 years in $18.3 \%$ of cases; between 10 and 20 years in $16.9 \%$ of cases; less than 5 years in $18.3 \%$ of cases.

We were able to find a few data to compare the training, prevalent clinical practice, and level of experience of the physicians who participated in our survey with those of respondents of other PD surveys.

In the PD survey carried out by Sullivan et al. (2015) among members of the American Urology Association, $75 \%$ of respondents described their practice as general urology; over half of respondents reported an interest in sexual medicine, $40 \%$ of respondents considered themselves as specialists in sexual medicine (52). In the PDsurvey by Oberlin et al. (2016), only 5.3\% of responding urologists also had a subspecialty in andrology (53).

In the PD survey by Shindel et al. (2008), out of the total number of urology specialists, $8.8 \%$ had received specific training in andrology (51).

In the Korean survey, the median duration of practice since completing specialty training was 12 years (range,
0-41 years); $59 \%$ of urologists had a clinical experience of over 10 years; $66 \%$ of respondents had seen fewer than five PD patients per year, while $16.6 \%$ of urologists managed more than $10 \mathrm{PD}$ patients per year (54).

\section{Conclusions}

The results of our survey indicate that Italian SIA uroandrologists, compared to their foreign counterparts, have a more proactive diagnostic approach right from when PD patients first present.

Furthermore, a preference for conservative medical treatment appears evident in our survey when PD is still in its active stage, at initial presentation, and in most cases; conservative treatment consists in oral therapy, which may be associated with physical treatment and injections. In advanced disease or in case of failure of the initial conservative treatment, our survey instead shows a greater preference for a surgical approach (corporoplasty with or without grafting, associated with prosthesis implant in case of associated ED). With regards to theoretical knowledge, the answers to our survey showed that Italian SIA physicians have in-depth knowledge of the etiology of the disease, its epidemiology, as well as its clinical presentation and correct therapeutic indications.

From the point of view of medical training, our survey found that $96.3 \%$ of SIA respondents is a specialist in Urology or a specialist in Andrology, while 10.8\% specialized in two fields (Urology, Andrology, or Endocrinology). Furthermore, $63.8 \%$ of Italian SIA physicians who participated in our survey reported having between 10 and over 20 years of experience in clinical practice.

\section{Collaborators}

(Uro-andrologists who participated in the survey): Andriani Egidio, Angelozzi Giovanni, Artegiani Antonio, Azzarito Giuseppina, Barletta Davide, Barrese Francesco, Belgrano Emanuele, Benvenuto Sara, Bianchi Bruno, Bierti Sergio, Bitelli Marco, Bizzotto Leonardo, Boeri Luca, Bottone Francesco, Branchina Antonino, Buono Girolamo, Caraceni Enrico, Casarico Antonio, Cassutti Valter, Castiglioni Mirco, Certo Marco, Chiancone Francesco, Cocci Andrea, Colombo Fulvio, Cornacchia Michele, Corretti Giorgio, Corvasce Antonio, D'Elia Carolina, De Grande Gaetano, De Luca Francesco, De Pasquale Filippo, De Santis Claudio, De Stefano Lorenzo, Dehó Federico, Della Camera Pier Andrea, Delle Rose Augusto, Di Domenico Dante, Di Filippo Aldo, Di Franco Carmelo Agostino, Di Gregorio Leonardo, Di Palma Paolo, Di Trapani Danilo, Fabiani Andrea, Fiordelise Stefano, Fiorillo Alessandro, Forte Saverio, Giammusso Bruno, Giovannone Riccardo, Godano Adriana, Granata Antonio Maria, Guerani Attilio, Guttilla Andrea, Iannotta Luca, Irianni Gabriele, Izzo Alessandro, La Pera Giuseppe, Lacava Gregorio, Larocca Lorenzo, Laruccia Nicola, Lauretti Stefano, Letizia Piero, Liguori Giovanni, Littara Alessandro, Mahlknecht Alois, Malvestiti Gianmario, Manica Michele, Manno Giuseppe, Maruccia Serena, Mastrocinque Giuseppe, Mavilla Luca, Mazziotti Raffaele, Mercenaro Maurizio, Michetti Paolo Maria, Milioto Vincenzo, Militello Andrea, Mondaini Nicola, Montalcini Gino, Morrone Giancarlo, Motta Maurizio, Natali Alessandro, Negro Carlo, Olivieri Valerio, Palumbo Fabrizio, 
Paolini Riccardo, Papini Alessandro, Passavanti Giandomenico, Paulis Gianni, Pavan Nicola, Pavone Carlo, Pescatori Edoardo, Pezzoni Fabio, Piubello Giorgio, Polito Chiara, Polito Massimo, Principi Emanuele, Ragni Francesca, Raimoldi Annibale, Ressa Gaetano, Risi Oreste, Rizzo Giorgio, Rolle Luigi, Ruoppolo Michele, Russino Giovanni, Russo Giorgio, Saccomanni Mauro, Salacone Pietro, Salhi Jamal, Salvia Giuseppe, Sarto Giuseppe, Savino Antonio, Scalvini Tiziano, Scroppo Fabrizio, Soli Marcello, Sorrentino Michelangelo, Speroni Alberto, Tiscione Daniele, Titta Matteo, Tripodi Vincenzo, Turchi Paolo, Ughi Gianni, Vagnoni Valerio, Vecchio Daniele, Vedovo Francesca, Vella Riccardo.

\section{REFERENCES}

1. Pryor JP, Ralph DJ. Clinical presentations of Peyronie's disease. Int J Impot Res. 2002; 14:414-417.

2. Nelson CJ, Diblasio C, Kendirci M, et al. The chronology of depression and distress in men with Peyronie's disease. J Sex Med. 2008; 5:1985-1990.

3. Weidner W, Schroeder-Printzen I, Weiske WH, et al. Sexual dysfunction in Peyronie's disease: an analysis of 222 patients without previous local plaque therapy. J Urol. 1997; 157:325-328.

4. Jarow JP, Lowe FC. Penile trauma: an etiologic factor in Peyronie's disease and erectile dysfunction. J Urol. 1997; 158:1388-1390.

5. Devine CJ, Somers KD, Jordan GH, et al. Proposal: trauma as a cause of Peyronie's lesion. J Urol. 1997; 157:285-290.

6. Devine CJ Jr, Somers KD, Ladaga LE. Peyronie's disease: pathophysiology. Prog Clin Biol Res. 1991; 370:355-358.

7. Somers KD, Dawson DM. Fibrin deposition in Peyronie's disease plaque. J Urol. 1997; 157:311-315.

8. Sikka SC, Hellstrom WJ. Role of oxidative stress and antioxidants in Peyronie's disease. Int J Impot Res. 2002; 14:353-360.

9. Davila HH, Magee TR, Vernet D, et al. Gene transfer of inducible nitric oxide synthase complementary DNA regresses the fibrotic plaque in an animal model of Peyronie's disease. Biol Reprod. 2004; 71:1568-1577.

10. Bivalacqua TJ, Champion HC, Hellstrom WJ. Implications of nitric oxide synthase isoforms in the pathophysiology of Peyronie's disease. Int J Impot Res. 2002; 14:345-352.

11. El-Sakka AI, Salabas E, Dinçer M, et al. The pathophysiology of Peyronie's disease. Arab J Urol. 2013; 11:272-277.

12. Paulis G, Romano G, Paulis L, et al. Recent pathophysiological aspects of Peyronie's disease: role of free radicals, rationale, and therapeutic implications for antioxidant treatment-literature review. Adv Urol. 2017; 2017:4653512.

13. Herati AS, Pastuszak AW. The genetic basis of Peyronie's disease: a review. Sex Med Rev. 2016;4:85-94.

14. Bias WB, Nyberg LM, Jr, Hochberg MC, et al. Peyronie's disease: a newly recognized autosomal-dominant trait. American journal of medical genetics. 1982; 12:227-235.

15. Rompel R, Mueller-Eckhardt G, Schroeder-Printzen I, et al. HLA antigens in Peyronie's disease. Urol Int. 1994; 52:34-37.

16. Willscher MK, Cwazka WF, Novicki DE. The association of histocompatibility antigens of the B7 cross-reacting group with Peyronie's disease. J Urol 1979; 122:34-35.

17. Schwarzer U, Sommer F, Klotz T, et al. The prevalence of Peyronie's disease: results of a large survey. BJU Int. 2001; 88:727-730

18. Dibenedetti DB, Nguyen D, Zografos L, et al. A population-based study of Peyronie's disease: prevalence and treat- ment patterns in the United States. Adv Urol. 2011; 2011:282503.

19. La Pera G, Pescatori ES, Calabrese M, et al. SIMONA Study Group Peyronie's disease: prevalence and association with cigarette smoking. A multicenter population-based study in men aged 50-69 years. Eur Urol. 2001; 40:525-530.

20. Deveci S, Hopps CV, O'Brien K, et al. Defining the clinical characteristics of Peyronie's disease in young men. J Sex Med. 2007; 4:485-490

21. Paulis G, Cavallini G, Barletta D, et al. Clinical and epidemiological characteristics of young patients with Peyronie's disease: a retrospective study. Res Rep Urol. 2015; 7:107-11.

22. Gonzalez-Cadavid NF. Mechanisms of penile fibrosis. J Sex Med2009; 6(Suppl 3): 353-362.

23. Paulis $G$, Brancato T. Inflammatory mechanisms and oxidative stress in Peyronie's disease: therapeutic "rationale" and related emerging treatment strategies. Inflamm Allergy Drug Targets. 2012; 11:48-57.

24. El-Sakka AI, Hassoba HM, Pillarisetty RJ, et al. Peyronie's disease is associated with an increase in transforming growth factor-beta protein expression. J Urol. 1997; 158:1391-1394.

25. Zimmermann RP, Feil G, Bock C, et al. Significant alterations of serum cytokine levels in patients with Peyronie's disease. Int Braz J Urol. 2008; 34:457-466.

26. Gentile V, Modesti A, La Pera G, et al. Ultrastructural and immunohistochemical characterization of the tunica albuginea in Peyronie's disease and veno-occlusive function. J Androl. 1996; 17:96-103

27. Mulhall JP, Schiff J, Guhring P. An analysis of the natural history of Peyronie's disease. J Urol. 2006; 175:2115-2118.

28. Hatzimouratidis K, Eardley I, Giuliano F, et al. EAU guidelines on penile curvature. Eur Urol. 2012; 62:543-552.

29. Garaffa G, Trost LW, Serefoglu EC, et al. Understanding the course of Peyronie's disease. Int J Clin Pract. 2013; 67:781-788.

30. Levine LA, Larsen S. Diagnosis and Management of Peyronie Disease. In: Wein AJ, Kavoussi LR, Partin AW, Peters CA, eds. Campbell-Walsh Urology. 11th Ed. ed Vol 1. Elsevier Saunders; Philadelphia: 2015. Chap 31 pp. 722-748.

31. Tsambarlis P, Levine LA. Nonsurgical management of Peyronie's disease. Nat Rev Urol. 2019; 16:172-186.

32. Nguyen HNT, Anaissie J, DeLay KJ, et al. Safety and efficacy of collagenase Clostridium histolyticum in the treatment of acute-phase Peyronie's disease. J Sex Med 2017; 14:1220-1225.

33. Zucchi A, Costantini E, Cai $T$, et al. Intralesional injection of hyaluronic acid in patients affected with Peyronie's disease: preliminary results from a prospective, multicenter, pilot study. Sex Med. 2016; 4:e85-e90.

34. Yafi FA, Pinsky MR, Sangkum P, et al. Therapeutic advances in the treatment of Peyronie's disease. Andrology. 2015; 3:650-660.

35. Gennaro R, Barletta D, Paulis G. Intralesional hyaluronic acid: an innovative treatment for Peyronie's disease. Int Urol Nephrol. 2015; 47:1595-1602.

36. Paulis G, Barletta D, Turchi P, et al. Efficacy and safety evaluation of pentoxifylline associated with other antioxidants in medical treatment of Peyronie's disease: a case-control study. Res Rep Urol. 2015; 8:1-10.

37. Paulis $G$, Brancato $T, D^{\prime}$ Ascenzo R, et al. Efficacy of vitamin $E$ in the conservative treatment of Peyronie's disease: legend or reality? A controlled study of 70 cases. Andrology. 2013; 1:120-128. 
38. Nehra A, Alterowitz R, Culkin DJ, et al. Peyronie's disease: AUA guideline. J Urol. 2015; 194:745-753.

39. El-Khatib FM, Towe M, Yafi FA. Management of Peyronie's disease with collagenase Clostridium histolyticum in the acute phase. World J Urol. 2020;38:299-304.

40. Ralph D, Gonzalez-Cadavid N, Mirone V, et al. The management of Peyronie's disease: evidence-based 2010 guidelines. J Sex Med. 2010; 7:2359-2374.

41. Kendirci M, Hellstrom WJ. Critical analysis of surgery for Peyronie's disease. Curr Opin Urol. 2004; 6:381-388.

42. Fabiani A, Fioretti F, Pavia MP, et al. Buccal mucosa graft in surgical management of Peyronie's disease: Ultrasound features and clinical outcomes. Arch Ital Urol Androl. 2021; 93:107-110.

43. Asali, M. Intralesional injection of the calcium channel blocker Verapamil in Peyronie's disease: A critical review. Arch Ital Urol Androl. 2020; 92:253.

44. De Rose AF, Ambrosini F, Mantica G, et al. Prepuce-sparing corporoplasty as a safe alternative for patients with acquired penile curvature. Arch Ital Urol Androl. 2020; 92:182.

45. Hatzimouratidis K, Eardley I, Giuliano F, et al. EAU guidelines on penile curvature. Eur Urol 2012; 62:543-552.

46. Nehra A, Alterowitz R, Culkin DJ, et al. Peyronie's disease: AUA Guideline. J Urol. 2015; 194:745-753.

47. Chung E, Ralph D, Kagioglu A, et al. Evidence-based management guidelines on Peyronie's disease. J Sex Med. 2016; 13:905-923.

48. Bella AJ, Lee JC, Grober ED, et al. Canadian Urological Association guideline for Peyronie's disease and congenital penile curvature. Can Urol Assoc J. 2018; 12:E197-E209.

49. Hauck EW, Bschleipfer T, Haag SM, et al. Assessment among German urologists of various conservative treatment modalities for Peyronie's disease. Results of a survey. Urologe A. 2005; 44:11891196

50. LaRochelle JC, Levine LA. A Survey of primary-care physicians and urologists regarding Peyronie's disease. J Sex Med. 2007; 4:1167-1173.

51. Shindel AW, Bullock TL, Brandes S. Urologist practice patterns in the management of Peyronie's disease: a nationwide survey. J Sex Med. 2008; 5:954-964.

52. Sullivan J, Moskovic D, Nelson C, et al. Peyronie's disease: urologist's knowledge base and practice patterns. Andrology 2015; 3:260264.

53. Oberlin DT, Liu JS, Hofer MD, et al. An analysis of case logs from American urologists in the treatment of Peyronie's disease. Urology. 2016; 87:205-209.

54. Ko YH, Moon KH, Lee SW, et al. Urologists' perceptions and practice patterns in Peyronie's disease: A Korean nationwide survey including patient satisfaction. Korean J Urol. 2014; 55:57-63.

55. DiBenedetti DB, Nguyen D, Zografos L, et al. A population-based study of Peyronie's disease: prevalence and treatment patterns in the United States. Adv Urol. 2011; 2011:9.

56. Stuntz M, Perlaky A, des Vignes F, et al. The prevalence of Peyronie's disease in the United States: a population-based study. PLoS One. 2016; 11:e0150157.

57. Weidner W, Schroeder-Printzen I, Weiske WH, Sexual dysfunction in Peyronie's disease: an analysis of 222 patients without previous local plaque therapy. J Urol. 1997: 157:325-328.

58. Kadioglu A, Sanli O, Akman T, et al. Factors affecting the degree of penile deformity in Peyronie disease: an analysis of 1001 patients. J Androl. 2011; 32:502-508.

59. Paulis G, Romano G, Paulis, A. Prevalence, psychological impact, and risk factors of erectile dysfunction in patients with Peyronie's disease: a retrospective analysis of 309 cases. Res Rep Urol. 2016; 8:95103.

60. Paulis G, Cavallini G. Clinical evaluation of natural history of Peyronie's disease: our experience, old myths and new certainties. Inflamm Allergy Drug Targets. 2013; 12:341-348.

61. Smith JF, Walsh TJ, Conti SL, et al. Risk factors for emotional and relationship problems in Peyronie's disease. J Sex Med. 2008; 5:21792184.

62. Gelbard MK, Dorey F, James K. The natural history of Peyronie's disease. J Urol. 1990;144:1376-1379.

63. Nelson CJ, Diblasio C, Kendirci M, et al. The chronology of depression and distress in men with Peyronie's disease. J Sex Med. 2008; 5:1985-1990.

64. Levine L, Rybak J, Corder C, et al. Peyronie's disease plaque calcification-Prevalence, time to identification, and development of a new grading classification. J Sex Med. 2013; 10:3121-3128.

65. Kadioglu A, Akman T, Sanli O, et al. Surgical treatment of Peyronie's disease: a critical analysis. Eur Urol. 2006; 50:235-248.

66. Kendirci M, Hellstrom WJ. Critical analysis of surgery for Peyronie's disease. Curr Opin Urol. 2004; 14:381-388.

67. Jalkut M, Gonzalez-Cadavid N, Rajfer J. Peyronie's disease: a review. Rev. Urol. 2003; 5:142-148.

68. Hellstrom WJ, Bivalacqua TJ. Peyronie's disease: etiology, medical, and surgical therapy. J Androl. 2000; 21:347-354.

69. Levine LA, Burnett AL. Standard operating procedures for Peyronie's disease. J Sex Med. 2013; 10:230-244.

70. Dolmans GH, Werker PM, de Jong IJ, et al. WNT2 locus is involved in genetic susceptibility of Peyronie's disease. J Sex Med. 2012; 9:1430-1434.

71. Sharma KL, Alom M, Trost L. The etiology of Peyronie's disease: pathogenesis and genetic contributions. Sex Med Rev. 2020; 8:314323.

72. Gonzalez-Cadavid NF. Mechanisms of penile fibrosis. J Sex Med. 2009; 6(Suppl. 3):353-362.

73. Chung E, De Young L, Brock GB. Rat as an animal model for Peyronie's disease research: a review of current methods and the peerreviewed literature. Int J Impot Res. 2011; 23:235-241.

\section{Correspondence}

Gianni Paulis, MD (Corresponding Author) - paulisg@libero.it Peyronie's Care Center, Department of Uro-Andrology, Castelfidardo Medical Team, Rome (Italy)

Francesca Pisano, MD - francescapisano85@gmail.com Department of Urology, Fundacio Puigvert, Autonomous University of Barcelona (Spain)

Alessandro Palmieri, MD - info@alessandropalmieri.it Department of Neurosciences, Reproductive Sciences and Odontostomatology, University of Naples Federico II, Naples (Italy)

Tommaso Cai, MD - ktommy@libero.it

Department of Urology, Santa Chiara Regional Hospital, Trento (Italy)

Fabrizio Palumbo, MD - palumbo.fab@gmail.com

Department of Urology, Di Venere Hospital, Bari (Italy)

Bruno Giammusso, MD - bgiammusso@hotmail.it

Urology Clinic, Policlinic "Morgagni", Catania (Italy) 